\title{
DETERMINATION OF FORMIC AND ACETIC ACIDS IN INDOOR AIR
}

Raluca Diodiu ${ }^{1,2}$, Elena Bucur ${ }^{1}$

${ }^{1}$ National Research and Development Institute for Industrial Ecology - INCD ECOIND, 71-73 Drumul Podu Dambovitei Street, 060652, Bucharest, Romania

${ }^{2}$ Babes-Bolyai University, Faculty of Environmental Science and Engineering, Fantanele 30, 400294, Cluj Napoca, Romania

\begin{abstract}
A method for the determination of formic and acetic acids was realized and validated in this work. The separation of the two organic acids was optimized in 10 minutes on an IonPac AS-18 column coupled with precolumns, isocratic mode, $0.250 \mathrm{ml} / \mathrm{min}$ flow and a mobile phase consisting in $\mathrm{KOH} 10 \mathrm{mM}$. The quantification of the interested compounds was done by external standard. Then, the method was validated by analyzing selectivity, linearity, limit of detection, limit of quantification, precision and accuracy. The validated method can be described as a simple and also low cost method for the determination of formic and acetic acid in air samplers.
\end{abstract}

Keywords: acetic acid, formic acid, indoor air, method validation

\section{Introduction}

Formic and acetic acids belong to the carboxylic acids group. This class of compounds is known to have a biological and applicability importance. They are used as antioxidants, acidifiers and drugs in pharmaceutical industry. Carboxylic acids were also involved in industrial organic syntheses and could be found as natural compounds, additives or preservatives in foods and beverages [1].

Formic acid, also called methanoic acid, it was obtained from ants, industrially is obtained from carbon monoxide and sodium hydroxide. Formic acid is a colorless, pungent odor, boils at $100.5^{\circ} \mathrm{C}$ and it is corrosive to skin; is the first in the carboxylic acids series and, also, it dissolves in water.

Formic acid is used in dyeing and finishing of textiles and paper, treatment of leather, electroplating and brewing, silvering glass, and as an intermediate in the manufacture of many chemicals. Formic acid is used also as preservative solutions[2].

Acetic acid, also called ethanoic acid, it is produced by the fermentation of alcohol (wine) after Scliuezenbach process. It follows a dilute acetic acid (4-6\%) as vinegar.

Acetic acid is a colorless liquid boils at $118{ }^{\circ} \mathrm{C}$; it tastes sour, pungent characteristic odor. Pure acetic acid is obtained by acetic acid rectification, and it is called technically pure glacial acetic acid. By cooling crystallizes, resulting comparable ice crystals, hence the name "glacial". 
Acetic acid is absorbed from the gastrointestinal tract and through the lungs. The acetate ion (the anion of acetic acid) is a normally-occurring metabolite in catabolism or in anabolic synthesis. It is estimated that the level of the acetate ion in humans is about $50-60 \mu \mathrm{mol} / \mathrm{l}(3.0-3.6 \mathrm{mg} / \mathrm{l})$ in plasma and $116 \mu \mathrm{mol} / \mathrm{l}(7$ $\mathrm{mg} / \mathrm{l})$ in cerebrospinal fluid [3], [4]. Daily turnover of the acetate ion in humans is estimated to be about $7.5 \mu \mathrm{mol} / \mathrm{kg} / \mathrm{min}$ representing some $45 \mathrm{~g} / \mathrm{day}$ [3], [5].

Estimations of the daily intake of acetic acid vary from about 1 gram [3], [6]. to $2.1 \mathrm{~g} /$ day for subjects older than 2 years [3], [7]. No adverse health effects are reported at these intakes [3].

Regarding ambient air, acetic and formic acid have been linked to increased formation of clouds and mists, increasing the acidity of rainwater, and corrosion of objects of cultural heritage, historic buildings and monuments.

The aim of this paper was to develop a simple and also low cost method for the determination of formic and acetic acid for ambiental and indoor air samplers.

\section{Materials and Methods}

For separation and quantification of acetic acid and formic was developed a method of analysis by ion chromatography. A Dionex ICS-5000+ Ion chromatograph model was used with integrated eluent generator equipped with a conductivity detector and anion suppressor (500 ORSA Dionex $2 \mathrm{~mm}$ ).

The type of the chromatography column plays the most important role in the separation of analytes. The literature indicates a large number of chromatography columns have been used in various case studies, best results were obtained with: IonPac AS $11 \mathrm{HC}$, IonPac AS-14, Allep A2, IC SI-50 4E [8], [9].

To separate the formic acid and acetic an lonPac AS-18 column chromatography coupled with precolumns recommended by the manufacturer to determine anions and low molecular weight organic acids was used.

Another important factor in chromatographic separation is the composition of the eluent [9]. We tested several compositions eluent and parameters of separation, choosing the combination that ensures separation of the two acids with the best resolution (resolution: 2.80), respectively: isocratic elution with $\mathrm{KOH} 10 \mathrm{mM}$, run time: 10 minutes, thermostatic detector and a column at $20^{\circ} \mathrm{C}$ and the injection volume of $5 \mu \mathrm{l}$. Figure 1 shows the chromatogram obtained from the separation of the two acids.

The calibration curves for the two acids were performed by external standard method, using standards acetate $1000 \mathrm{mg} / \mathrm{ml}$, and formate $1000 \mathrm{mg} / \mathrm{ml}$, purchased from LGC Standards.

The curves were plotted in six points (STD) which covered areas of work between 10 and $1,000 \mathrm{mg} / \mathrm{ml}$ for acetic acid and 4 and $400 \mathrm{mg} / \mathrm{ml}$ formic acid, found in areas corresponding concentrations for literature studies conducted in indoor air. Concentrations of the six calibration standards are listed in Table 1.

Table 1. Concentration in $\mathrm{mg} / \mathrm{L}$ of the standards from the calibration curve

\begin{tabular}{r|cccccc} 
& STD 1 & STD 2 & STD 3 & STD 4 & STD 5 & STD 6 \\
\hline Acetic acid & 10 & 50 & 100 & 250 & 500 & 1000 \\
Formic acid & 4 & 20 & 40 & 100 & 200 & 400
\end{tabular}




\section{Results and Discussion}

The aim of this work was to validate and develop a method in order to apply it to the quantitation of the carboxylic acids in indoor air samplers. According to Eurachem Guide [10], method validation is the process of defining an analytical requirement, and confirming that the method under consideration has capabilities consistent with what the application requires.

Analytical method performance parameters achieved in this work for determining acetic and formic acid were: detection limit, quantification limit, selectivity, linearity, repeatability and accuracy.

Analytical selectivity relates to the extent to which the method can be used to determine particular analytes in mixtures or matrices without interferences from other components of similar behavior [11].

The selectivity of the method is expressed by the resolution between the peaks of interest. For the two compounds, a good resolution was observed between the peaks of acetic and formic. Resolution $>2$ between the peak of interest and the closest potential interfering peak (impurity, excipient, degradation product, internal standard, etc.) is desirable. The separation between the peaks can be seen in Figure 1.

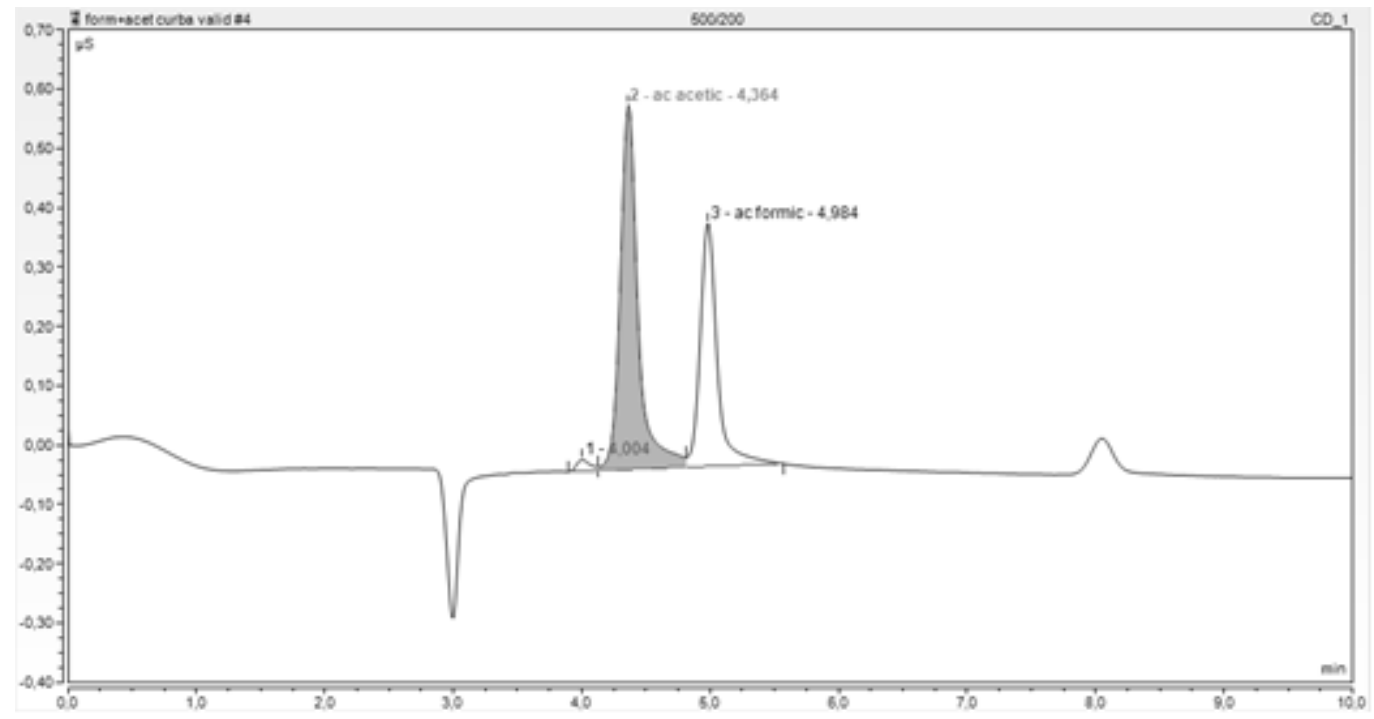

Fig. 1. Formic acid and acetic acid separation column lonPac AS 18

Linearity of an analytical procedure as its ability (within a given range) to obtain test results that are directly proportional to the concentration (amount) of analyte in the sample. The working range determines the analyte concentration range for which the method can be applied. Within the working range there may be a linear range of response to linearity condition that applies to the correlation coefficient. The linearity of the method was evaluated in the concentration ranges from Table 1 by plotting concentrations obtained by applying the whole method against introduced concentration for each carboxylic acid. For each concentration three independent solutions were prepared. Good coefficients of 
determination were obtained greater than 0.999 (formic acid $r^{2}=0.99937$ and acetic acid $\left.r^{2}=0.99996\right)$. The calibration curves obtain can be seen in Figure 2 .
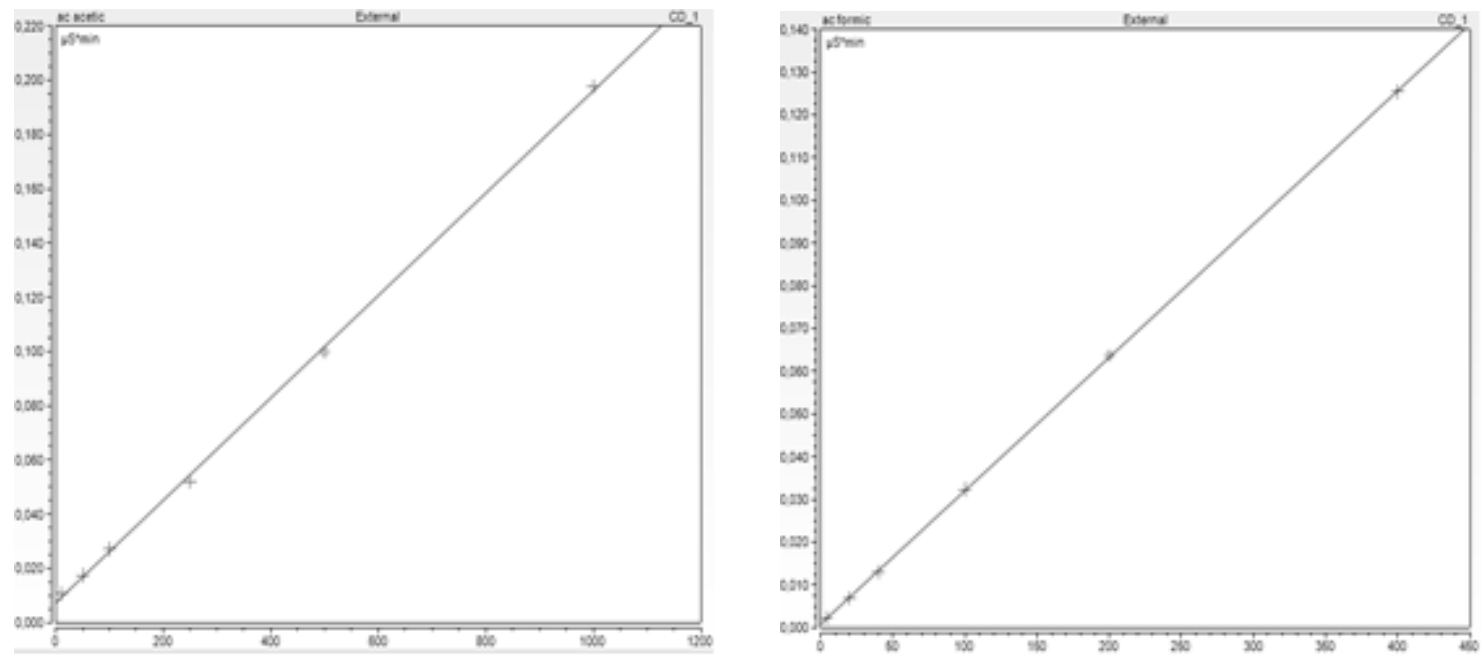

Fig.2. Calibration curves: acetic acid (left) and formic acid (right)

The detection limit (LOD) is the lowest concentration that can be measured with reasonable statistical certainty, is the analyte concentration corresponding to a signal detector equal to the blank media plus 3 times the standard deviation. Limit of quantification (LOQ) is the analyte concentration corresponding to a signal detector equal to the blank media plus 10 times the standard deviation. The LOD and LOQ for the presented method can be seen in Table 2.

Table 2. Performance parameters of the analytical method

\begin{tabular}{rcc}
\hline & Acetic acid & Formic acid \\
\hline Detection limit $(\mu \mathrm{g} / \mathrm{L})$ & 0.20 & 0.25 \\
Limit of quantification $(\mu \mathrm{g} / \mathrm{L})$ & 0.64 & 2.1 \\
Repeatability & 5.87 & 6.29 \\
Accuracy & 3.13 & 4.85 \\
\hline
\end{tabular}

Precision (measurement precision) is a measure of how close results are to one another. It is usually expressed by statistical parameters which describe the spread of results, typically the standard deviation. The precision of the method was evaluated for a concentration of $200 \mu \mathrm{g} / \mathrm{L}$ for acetic acid and $80 \mu \mathrm{g} / \mathrm{L}$ for formic acid and can be seen in Table 2 as Repeatability.

The Accuracy of an analytical procedure is the closeness of agreement between the conventional true value or an accepted reference value and the value found.

To evaluate the accuracy of the method, a synthetic industrial reaction mixture free from the two carboxylic acids was prepared. The values obtained for the accuracy of this method can be seen in Table 2 .

This ion chromatographic method was now validated, which ensured its performance level was compatible with its objectives. 


\section{Conclusions}

This method for identification and quantification of acetic acid and formic acid can be applied both in indoor air samples and in those taken from the ambient air.

This method can be successfully used in the determination of organic acids in homes, offices, museums, archives and other heritage buildings, having the advantage of being able to determine the concentration of acetic and formic acid simultaneously and in a short time.

\section{Acknowledgements}

The tests have been done inside the Program Nucleu financed by the Ministry of Education and Research of Romania whom we thank with this opportunity for all the support.

\section{References}

1. E. Destandaua, J. Viala, A. Jardya, M.-C. Henniona, D. Bonnetb, P. Lancelinb (2005), Development and validation of a reversed-phase liquid chromatography method for the quantitative determination of carboxylic acids in industrial reaction mixtures, Journal of Chromatography A, 1088, 49-56.

2. Health Council of the Netherlands: Committee on Updating of Occupational Exposure Limits. Formic acid; Health-based Reassessment of Administrative Occupational Exposure Limits. The Hague: Health Council of the Netherlands, (2005); 2000/15OSH/149.

3. Recommendation from the Scientific Committee on Occupational Exposure Limits for acetic acid, SCOEL/SUM/98, June (2012)

4. Lentner C, ed (1984). Geigy Scientific Tables. 8th ed. Vol 1. Units of Measurement, Body Fluids, Composition of the Body, Nutrition. Vol 3. Physical Chemistry, Composition of the Blood, Hematolgy, Somatometric Data. CIBA-GEIGY Limited, Basel, Switzerland.

5. Simoneau C, Pouteau E, Maugeais P, Marks L, Ranganathan S, Champ M, Krempf M (1994). Measurement of whole body acetate turnover in healthy subjects with stable isotopes. Biol Mass Spectrom 23:430-433.

6. Elias PS (1987). The public's response to decontamination. In: Smulders FJM, ed. Elimination of pathogenic organisms from meat and poultry, Amsterdam, Elsevier, 345-361. Reported in Food Preservation techniques. Edit by $\mathrm{P}$ Zeuthen and L Borg-Sorensen. Woodhead Publishing.

7. Katz GV, Guest D (1994). Aliphatic Carboxylic Acids. In: Clayton GD, Clayton FE, eds.

Toxicology. 4th Edition. New York: John Wiley \& Sons: 3523-3671. (Patty's Industrial Hygiene and Toxicology, Vol II, Part E).

8. Hodgkins R., Grzywacz C., Garrell R. (2011): An improved ion chromatography method for analysis of acetic and formic acid vapours, e-PS, 8, 74-80 ISSN: 1581-9280 web edition

9. Kotonova-Deutsch V., KRATA A., Deutsch F., Bencs L., Van Grieken R. (2008): Efficient separation of acetate and formate by ion chromatography: application to air samples in a cultural heritage environment. Talanta, 75, 418-423.

10. B. Magnusson and U. Örnemark (eds.) Eurachem Guide (2014): The Fitness for

Purpose of Analytical Methods - A Laboratory Guide to Method Validation and Related Topics, (2nd ed. 2014).ISBN 978-91-87461-59-0. Available from www.eurachem.org.

11. Selectivity in analytical chemistry (IUPAC recommendations 2001), (2001) Pure Appl. Chem., 73(8), 1381. 